\begin{tabular}{|c|c|c|c|}
\hline$\Omega$ & [1] & $\equiv$ & (2) \\
\hline Georgia & 'Dept of Respiratory Medicine, King's College & Georgia Hardavella & georgiahardavella@hotmail.com \\
\hline Hardavella ${ }^{, 1,2}$, & $\begin{array}{l}\text { Hospital, London, UK } \\
\text { 2Dept of Resniratory Medicine and Alleroy King's }\end{array}$ & & \\
\hline Neil Saad3, & College Hospital, London, UK & & \\
\hline Anders Bjerg4 & $\begin{array}{l}{ }^{3} \text { National Heart and Lung Institute, Imperial College } \\
\text { London, London, UK } \\
\text { 4Krefting Research Centre, University of } \\
\text { Gothenburg, Gothenburg, Sweden }\end{array}$ & & \\
\hline
\end{tabular}

\title{
Doing Science: managing colleagues and collaborations in scientific research
}

\section{Introduction}

Talent, dedication and organisational skills play a pivotal role in the success of scientific and clinical research. However, your capacity to flourish and succeed is often affected by your professional relationships with your peers and bosses. Throughout your career, you will be faced (if not already) with a variety of awkward interpersonal situations. This is the point where sophisticated management skills are required to tackle difficulties and smooth out any rough edges that can potentially roadblock your research.

Managing professional relationships on these grounds can be complex and includes (but is not limited to) employing a variety of skills (especially communication) depending on which colleague you are dealing with: your boss, peers or external collaborators.

\section{How to manage a difficult relationship with your boss}

As a PhD student or postdoctoral researcher you will be working with a senior academic supervisor. It is very important that the "rules", working plan, congress attendances/presentations, publications, authorships and how the boss will support you are clarified from the outset. It's important that both sides agree on the ground rules and know what is expected. Consequently, it is easier to establish the cause if something goes wrong in the future.

However, if the relationship does break down (even after agreeing the ground rules), how do you handle it?

First, establish what the cause of the problem is. Did you both interpret something differently? Is your supervisor experiencing some personal problems? Did you not read their latest email? A useful tip is to keep a record when you think something is going wrong in the relationship. This will help you find the cause of the problem.

Secondly, once you have identified the problem, think of solutions and, when you feel ready, have a chat. Be honest, outline what the problem is and present the solution. If this solves the problem, well done! If it doesn't or if you can't identify the problem/solution or simply don't want to have a meeting about it, get help immediately. Most universities will have student and postdoctoral representatives and often senior academics for welfare support and a counselling service. A neutral third party can help you with how to proceed. Many institutions assign independent advisors to $M D$ and PhD students or post-doctoral researchers who can be approached as a
Conflict of interest

None declared.
HERMES syllabus link: module F.1, F.3, F.7 
Table 1 How to manage the relationship with your supervisor: common problems and solutions

\begin{tabular}{ll}
\hline Common problems & Potential solutions \\
\hline $\begin{array}{l}\text { Unsupportive supervisor, doesn't have } \\
\text { enough time for you or doesn't offer } \\
\text { enough help }\end{array}$ & $\begin{array}{l}\text { All supervisors are very busy. Establish a meeting to express your concerns. If they're not } \\
\text { sticking to that, call them on it. If unresponsive, think about speaking to the head of group } \\
\text { or department (PhD students should speak to the postgraduate research/course director) } \\
\text { or an independent advisor. }\end{array}$ \\
\hline $\begin{array}{l}\text { Supervisor does not share credit for the } \\
\text { work }\end{array}$ & $\begin{array}{l}\text { Again, discuss this. Keep an accurate record of your work and contribution and outline why } \\
\text { you deserve a spot on the publication/abstract (even as first or senior author). }\end{array}$ \\
\hline $\begin{array}{l}\text { Supervisor is asking you to do work } \\
\text { outside your project/PhD which is } \\
\text { taking up too much time }\end{array}$ & $\begin{array}{l}\text { Refer to the planning you agreed. For PhD students, you can speak to your course director } \\
\text { as you are expected to finish a PhD and not solely work on a side project that's taking up all } \\
\text { your time. For postdocs, the situation can be difficult as the supervisor who is likely funding } \\
\text { you can change the research focus/project. Discuss the changing focus/work and make it } \\
\text { clear why it isn't manageable. }\end{array}$ \\
$\begin{array}{l}\text { Supervisor's research views/values/ } \\
\text { opinion differs from yours }\end{array}$ & $\begin{array}{l}\text { Preferably you want to know this in advance. People have different opinions in science; this } \\
\text { is what makes it interesting. Always share your views politely but if you really don't believe } \\
\text { in the research you are doing then you're probably not in the right lab. }\end{array}$ \\
\hline $\begin{array}{l}\text { Supervisor is bullying, harassing or } \\
\text { discriminating against you }\end{array}$ & $\begin{array}{l}\text { Keep a record of events and, if you feel comfortable, discuss it with your supervisor to make } \\
\text { it clear that this is unacceptable. Otherwise, or if that doesn't help, look up what procedure } \\
\text { is in place at your university or institute and contact the appropriate people. }\end{array}$ \\
\hline
\end{tabular}

neutral person when difficulties arise. This enables the researcher to speak up and communicate concerns if required without having the underlying fear that their future career might be jeopardised. This has proven to be an efficient way of defusing tensions and moving on in a productive way. Try to explore this option and make yourself aware of this or any other similar existing buffer mechanisms in your institution as soon as you sign up, don't wait for tensions to arise first! Common relationship problems with your supervisor and suggested approaches are listed in table 1.

Never forget that science and your relationship with your supervisor is a two-way process: communication is essential. Establish ground rules and speak to your supervisor if you think there's a problem and ask them to do the same.

\section{How to manage a difficult relationship with a colleague}

We all may know one or more difficult colleagues and may even be considered one ourselves; the one who is always picking on people at the lab meetings or steals others' ideas and presents them as their own or who always manages to talk his/her way out of the most unpleasant night shifts.
Understanding group dynamics and how conflicts are addressed at your specific workplace is important. In some groups, all conflicts should be run through superiors, while in other contexts, minor disputes are expected to be resolved between the adversaries and going through superiors is considered unnecessary or even "snitching". For certain conflict types, an organisation may have established policies and points of contact, e.g. for reporting discrimination or sexual harassment.

Assuming, however, that you are supposed to resolve the conflict yourself, try to keep calm and leave your ego behind. Look at the conflict situation, the "difficult" colleague, yourself and the group soberly, and try different angles. Maybe you have a trusted friend, preferably one outside the group, to whom you could turn and seek a critical discussion, where your own position and perspective will be challenged?

If you choose to talk to colleagues be aware that, in general, involving more people may rapidly expand the conflict and may have the potential to let the situation get out of hand.

Alternatively, perhaps your adversary is considered a difficult colleague by several people, and the overall picture is grave enough to take action together. The perspective to which your own reflections and discussions with peers have led to will be very helpful. The opinions of others should 
however not be used; instead, you need to give concrete examples of the situations that made you perceive a conflict. Try to reach some common ground as to what has actually happened. This leads to your own experience, which is best conveyed in wordings such as "I felt that...", which leaves your adversary room to understand what has been going on inside you. Be ready to listen more than you speak, since you have had time to think your own perspective through, but are not prepared for that of your adversary. You may have different opinions as to what happened and, even if you get upset, you should keep calm and focus on resolving the situation. As important as it is to speak freely, conflicts are much easier to escalate than to de-escalate.

However, some conflicts just cannot be resolved. If forgiving and moving on is not an option, just try to avoid the person in question. Some bosses can be very helpful in that, as it is not uncommon that certain colleagues do not go well together, and constant conflicts are not in the interest of the group. You may, however, end up in a situation where the difficult colleague continues to cause you trouble, and cannot be avoided. If you cannot cope, you should consider changing to another group altogether. Conflicts may be the result of one person but arise out of the social environment. And perhaps that is an environment you do not want to be part of.

\section{How to manage difficult external collaborators (i.e. they have a different boss)}

External collaborators in research could be people sharing their samples with you or providing you with samples, consulting in specific techniques, etc. But by no means are people who share reagents or consumables with you!

Sometimes external collaborators may be co-applicants in your funding application for your $\mathrm{PhD} /$ postdoctoral project and this is when things can be more difficult.

Difficult relationships with external collaborators should be informally escalated to your boss from the beginning. They will be able to advise you on how to navigate these relationships and avoid unpleasant surprises that your lack of experience could trigger.
As in the previous situations, try to identify the difficult point in the relationship. In the majority of cases, it is disagreement about authorship, intellectual property issues, loss of interest in project, stealing credit or disparaging you to others. Try to identify and understand what the overall issue is. It is useful to create a flow diagram of your collaboration with the other party and identify the time points of conflicts, as it is then easier to go back and do a root-cause analysis of what went wrong and most importantly what could be done differently in the future to avoid similar incidents from happening again. Also try to compare it against the initial agreement that was made between the two interested parties and see where the lines were crossed.

Documenting everything by email is a good practice and copying in your own boss is recommended, as it ensures you all have the same understanding and are up to date. Email threads may be considered boring and overwhelming but they can be essential elements when resolving conflicts or miscommunications.

If the issue cannot be resolved, then it is the time for a face-to-face meeting with all parties involved and you are advised to follow the overall approach described in previous sections.

Always remember to send an email after the meeting thanking everyone for their attendance and summarising what you have mutually agreed on and don't forget to copy your boss in on the email.

As external collaborations can sometimes be fairly political, it is advised that you take any solutions through your boss and kindly put them in the lead position to resolve the case, especially if that means stepping back from the collaboration or renegotiating collaboration rules.

Difficult professional relationships when doing research can be incredibly destructive to good teamwork and, if managed in the wrong way, they may threaten the group's mission and result in the breakdown of cooperation. Overall, try to take a positive approach to resolving these by discussing in a courteous and non-confrontational manner and by focusing on issues rather than on individuals. Managing colleagues and collaborations in research entails mastering the art of communication.

\section{Further reading}

1. Roche WK. The Oxford Handbook of Conflict Management in Organizations. Oxford, Oxford University Press, 2014

2. Gallo A. How to Deal with a Mean Colleague. Harvard Business Review, October 16, 2014.

3. Fairweather A. How to manage difficult people. Proven Strategies for Dealing with Challenging Behaviour at Work. London, Rightway, 2014. 